\title{
The Early Bird and the Late Bird: Which Catches More Worms in Australia?
}

\author{
Nirodha I. Jayawardena ${ }^{\mathrm{a}}$, Akihiro Omura*, Bin Li ${ }^{\mathrm{b}}$
}

*Corresponding author: Graduate School of Business Administration, Meiji University, Japan. Email: akihiro_omura@meiji.ac.jp

\footnotetext{
a Department of Accounting, Finance and Economics, Griffith Business School, Griffith University, Nathan, Queensland 4111, Australia. E-mail: nirodhaimali.jayawardena@griffithuni.edu.au

${ }^{\mathrm{b}}$ Department of Accounting, Finance and Economics, Griffith Business School, Griffith University, Nathan, Queensland 4111, Australia. E-mail: b.li@griffith.edu.au.
} 


\title{
The Early Bird and the Late Bird: \\ Which Catches More Worms in Australia?
}

\begin{abstract}
Purpose - The purpose of this study is to examine what the optimal time is in a typical trading day for investors to buy/sell stocks in the Australian stock market.

Design/methodology/approach - The study mainly focuses on the S\&P/ASX200. Each trading day, between 10:00 am and 4:00 pm, is divided into 30-minute blocks. The effectiveness of easily implementable trading strategy to purchase the index in the morning and sell at the close is tested. The study controls for the excess overnight price volatility to improve the effectiveness of the investment strategy. This trading strategy is compared against other sixty-six possible daytrading combinations.

Findings - The results show that the trading strategy of buying in the first $\mathbf{3 0}$ minutes of the trading session and close off the position during the last $\mathbf{3 0}$ minutes obtains higher returns than other sixty-six strategies.

Practical implications - The day-trading strategy proposed in this study is very simple and therefore can be easily implemented by investors including individual investors.

Originality/value - To the best of our knowledge, this is the first study which constructs a trading strategy using the $\mathrm{J}$ - or $\mathrm{U}$-shaped intraday return pattern.
\end{abstract}

Keywords: Trading time, intraday data, Australian market, stock market

Paper type: Research paper 


\section{Introduction}

Can the early bird catch more worms than the late bird? The timing is critical in the investment world, and thus "when is the optimal time to trade" is an everlasting question for investors. Improvements in the availability of high frequency financial data have enabled academic researchers and financial market traders to conduct intraday technical analysis on stock markets. By utilising such data, we examine when the best time of a day is to trade in the Australian Securities Exchange (ASX).

It is not surprising that many past studies, which use high frequency data, focus on the impact of information flow (such as announcements of governments and companies) on the stock market. Those studies include Groß-Klußmann and Hautsch (2011), Hautsch et al. (2011), Kalev et al. (2004), Ohara (2014), and Smales (2014a). Though the findings of those studies may help investors construct their own trading strategies, the implementation of such strategies can be complex. We therefore aim to apply a much simpler trading strategy by identifying intraday low and high prices that are likely to be recorded during the trading session. Our study is inspired by previous research documenting intraday patterns in the trading activities of financial products (e.g., Ying 1966; Wood et al. 1985; Admati \& Pfleiderer 1988; Jain \& Joh 1988; Mcinish \& Wood 1990; Mcinish \& Wood 1992; Choe \& Sik Shin 1993; Aitken et al. 1994; Brailsford 1995; Madhavan et al. 1997; Ahn \& Cheung 1999; Andersen et al. 2000).

In particular, Wood et al. (1985) and Mcinish and Wood (1990) report that in the U.S. stock market, high returns tend to be observed in the early and the end of the day. In relation to the intraday trend in the equity returns, Harris (1986) also documents that 
in general, intraday returns of the equally-weighted New York Exchange portfolio show somewhat a J-shaped pattern. His study further shows that, in most of the days of the week, the intraday cumulative return sharply increases in the early morning period and then peaks out until around the close of the day where we see a further advance in such a return. This suggests that the price around the opening (closing) tends to be the lowest (highest) during the day, unless large negative returns are obtained at the trough of the intraday return curve. Furthermore, Jain and Joh (1988) present a similar pattern in the intraday S\&P 500 index returns.

This intraday pattern in the stock market returns may be explained in the context of the relationships among returns, price variability and trading volume. Jain and Joh (1988) report somewhat an inverted J-shaped pattern in the intraday return path as well as a U-shaped pattern in the trading volume (i.e., the highest volume is recorded in the first hour of the day, and the volume decreases in the following several hours before bouncing back near the close of the market). They rationalise this phenomenon as an effect of the overnight and the early morning information being absorbed by the market around its opening. The positive relationship between the return and the trading volume of the S\&P 500 index is also shown in Ying (1966).

In addition, as documented in studies like Wood et al. (1985), Harris (1986), Mcinish and Wood (1990) and Madhavan et al. (1997), variability of the intraday stock market returns also follow an inverted J-shaped or a U-shaped pattern. To explain this volatility trend, Admati and Pfleiderer (1988) present the theory of trading patterns in financial markets, which centres on informed and liquidity traders. Admati and Pfleiderer argue that it is difficult for traders to conduct trading activities during the 
periods before the opening and after the closing. For this reason, discretionary liquidity traders (ones who can decide when to trade) tend to concentrate their executions around the opening and the closing to satisfy their trading needs during the non-trading interval. It is obvious that informed traders would wish to trade when the market is thick and for this reason, the trading activities of informed traders also intensify around the opening and the closing of the market. As a result of increase in the participation of informed traders, the stock market tends to fluctuate more during those hours.

Kalev et al. (2004) also relate the intraday price variability pattern to the amount of information delivered to the market. More specifically, they argue that the news arrival process affects the intraday pattern observed in the price volatility. There are studies that document similar trends in the Australian stock market (e.g., Aitken et al. 1994; Brailsford 1995; Kalev et al. 2004). The market volatility may be one of the key factors affecting the stock market returns to follow the aforementioned intraday pattern. For this reason, investors may need to control the market volatility in order to develop an effective day-trading strategy by incorporating the intraday pattern of stock price.

Helping investors to construct their investment strategies is one of the goals of understanding the characteristics of stock markets and, to the best of our knowledge, this is the first study which constructs a trading strategy using the $\mathrm{J}$ - or U-shaped intraday return pattern. Since untradeable period that divides trading days is an important factor causing executions to intensify around opening and closing of an exchange market, this study focuses on the ASX, one of the largest stock markets that do not offer 24-hours trading service.

The day-trading strategy proposed in this study is very simple and therefore can 
be easily implemented by investors. Specifically, we buy the index during the first 30 minutes and close this position during the last 30 minutes of the trading session of the same day, when the excess overnight volatility of the S\&P/ASX 200 market index on a certain day is negative. As mentioned above, the stock price return and its volatility level are assumed to be positively related and the performance of our strategy may be negatively affected by the extreme level of market volatility. To overcome this issue, we filter the volatility level in executing our trading strategy. As documented in Jayawardena et al. (2016), an overall fluctuation of the price in a certain day is affected by the overnight price variation from the previous trading day. We use the overnight volatility as a proxy to measure expected market variation during the following day.

Recently, Wu et al. (2017) analyse the performance of simple trading strategies on the TAIEX futures in the Taiwan Stock Exchange. They show that the distribution pattern of daily returns obtained from purchasing in the market opening and selling at close is somewhat symmetrical, having zero return in the middle. This is another reason why we give a twist to the simple trading strategy that we explained above. Based on this, our trading strategy takes overnight volatility into consideration.

We find that our proposed strategy provides statistically higher returns than the returns obtained from other sixty-six possible day-trading combinations. The regression analysis further confirms that the returns obtained in our strategy are not associated with a higher risk. Our trading method is as simple as trading strategies like the "10 a.m. trading rule" which recommends investors to only purchase a stock if the price after 10 a.m. exceeds the price recorded prior to 10 a.m. (Ultimate Trading Systems 2005). Thus, it can be easily and cheaply implementable by both institutional and individual 
investors. In addition, our findings contribute to the studies on intraday pattern in the stock market activities.

\section{Data, Method and Results}

The data originates from the Thomson Reuters Tick History database via the Securities Industry Research Centre of Australia (SIRCA) portal, and covers the period 2 October 2000 - 2 October 2015, with a total of 3,788 trading days. It consists of intraday observations measured at 15-minute, which are aggregated to compute 30minute blocks of the spot prices of the S\&P/ASX 200 market index. Each trading day has 6 hours of trading at the ASX, spanning from 10:00 a.m. to 4:00 p.m.

To confirm the presence of the intraday price pattern, we standardise the market index by computing the relative average price (the deviation from the average price) in the $i^{\text {th }}$ block of day, $D A P_{i, t}$. The relative average price is estimated as

$$
D A P_{i, t}=\left(\frac{p_{i, t}-\bar{p}_{i, t}}{\bar{p}_{i, t}}\right), \quad i=1,2, \ldots, 12
$$

where $p_{i, t}$ is the price in the $i^{\text {th }}$ block of day $t$ and $\bar{p}_{i, t}$ is the average price in day $t$. For each day $t$, we identify the block $i$ with the lowest $D A P_{i, t}$ and the highest $D A P_{i, t}$ respectively.

The descriptive statistics in Table 1 display an inverted J-shaped pattern in the standard deviations of the relative average prices of the S\&P/ASX 200. Also, we observe a J-shaped pattern in the mean of the relative average prices (also see Figure 1). This implies that stocks in the Australian market tend to be the cheapest in the first 30 minutes of the day. 
[Insert Figure 1 and Table 1]

Next, we divide the dataset by year to check whether the intraday pattern is time varying. Table 2 shows the proportion of the trading days within a certain year where the price during a specific time block is found to be the lowest or the highest during the day. The first block is shown to have the largest number of days of the lowest prices in eleven years out of our sample period of sixteen years. In contrast, in twelve years out of our sample period, the last-time block records the largest number of days of the highest price. Hence, the intraday price pattern found in Table 1 does not substantially vary over time.

To check whether a certain industry or company is leading this phenomenon, we check the intraday price pattern of three major Australian industries, namely, the industrial sector, the resources sector and the financial sector; and four major companies listed in the ASX 200, namely, Commonwealth Bank of Australia (CBA), BHP Billiton Limited (BHP), Australia and New Zealand Banking Group Limited (ANZ), and National Australia Bank Limited (NAB). Table 3 presents the means and standard deviations of those. The results confirm the J-shaped patterns in the relative average price values and the U- or inverted J-shaped patterns in the variability of those values in the industry and individual stock levels, except for CBA.

[Insert Tables $2-3]$ 
We now apply the aforementioned findings to construct a trading strategy and examine its effectiveness. As the stock price tend to be cheaper in the early morning than around the close, we purchase one trading unit of the S\&P/ASX 200 every day during the first time block (10:00 - 10:30 a.m.) and then sell it during the last time block (3:30 - 4:00 p.m.) in the same day. We first execute our strategy without controlling for the factor of price variation (the results are available on request). As expected, this strategy fails to obtain favourable returns, but rather generates an average of 1 per cent losses, in an annualised form.

We suspect that the high price variability in the market during the early morning (volatility of the DAP in the first block is approximately three times higher than that of the late afternoon) is directly affecting the performance of our strategy. To check the relationship between the excessive level of volatility and the stock market return, we conduct a regression analysis using the daily returns of S\&P/ASX 200 index as a dependent variable and the overnight excess price volatility as an independent variable. The overnight volatility is measured by $\left(P_{\text {open }, t} / P_{\text {close }, t-1}\right)^{2}$, where $P_{\text {close }, t-1}$ represents the close price of the previous day and $P_{\text {open,t }}$ represents the open price of the current day. Then the excess overnight volatility is estimated by taking the difference between the overnight volatility of a certain day and its past 12-month average. As depicted in the result below, the daily return series is a negative function of the excess overnight volatility at the 10 per cent significance level (based on the White robust standard error). Thus, the stock market return is negatively affected when the excessive level of price variability is expected on the day. 


$$
\begin{aligned}
& \text { Daily return }_{t}=\beta_{0}+\beta_{1} \times \text { Excess overnight volatility } \text { vi-1 }_{t}+\varepsilon_{t} \\
& \text { Daily return }_{t}=-0.0002-0.0112 \times \text { Excess overnight volatility }_{t-1} \\
& \left.(\mathrm{p} \text {-value }=0.05) \quad(\mathrm{p} \text {-value }=0.07) \quad \text { (Adjusted } \mathrm{R}^{2}=0.002\right)
\end{aligned}
$$

Based on the above finding, we re-construct the trading strategy as follows. We enforce our strategy (buy at the $1^{\text {st }}$ block and sell at the last block) only when the excess overnight price volatility is negative. The return obtained from this is compared against other sixty-six possible day-trading arrangements when the trading session is divided into 30-minute blocks. In particular, for the sixty-six trading combinations, we construct situations where buying one unit of the S\&P/ASX 200 during one of the 12 time blocks for all our sample days, and then sell it during one of the later block times. For example, buying the S\&P/ASX 200 during the first block and then sell it during the second block, third block or fourth block. As a result, the performance of our strategy is convincing (Table 4). It obtains 9.3 per cent annualised average return over the sample period, which is considerably higher than any other day-trading combinations. Furthermore, based on the pair-wise $t$-test which examines the difference between returns obtained from our strategy and each of other sixty-six trading combinations, the performance of our strategy is found to be statistically higher at the 1 per cent significance level (Table $5)$.

[Insert Tables 4 - 5] 
Furthermore, we extend our analysis by evaluating whether the returns obtained from our strategy is associated with a higher risk. To check this, we analyse the contemporaneous risk-return relationship by regressing the holding period return of our trading strategy against the realised volatility of the S\&P/ASX 200 index. The result reported below confirms that the returns are not significantly affected by the realised volatility even at the 1 per cent significance level.

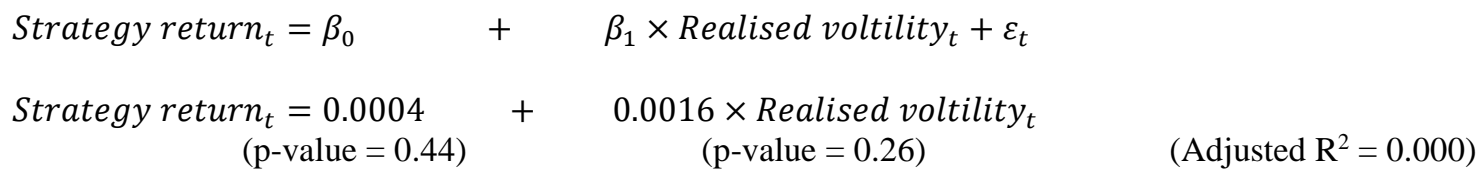

Finally, we compare the Sharpe ratios of our strategy and other sixty-six trading combinations to examine whether our strategy provides a higher holding period return even after adjusting for the risk. To estimate the Sharpe ratio, we use the cash rate published by the Reserve Bank Australia to represent the risk-free return. The results in Table 6 show that our trading strategy yields a positive ratio of 2.5 while other possible day-trading combinations obtain negative values.

\section{[Insert Table 6]}

\section{Conclusion}

To answer the question "when is the optimal time to trade", we conduct a study by dividing the ASX trading session into 12 time blocks and analyse the intraday high and low prices of selected assets traded on the ASX. We find that for the period 20002015 the prices are usually lowest during the 10-10:30 a.m. block, which is the best 
time to buy; and the lowest in the last time block before the close, which is the best time to sell. In light of this, we develop a simple trading strategy wherein investors buy a unit of the S\&P/ASX 200 in the early morning and sell it in the time block just before the close when the excess overnight price volatility is negative. By filtering the expected excess variation of the intraday price in executing the trading, our day-trading strategy achieves statistically higher returns than other sixty-six possible day-trading combinations through dividing the trading hours into 30-minute blocks. The riskadjusted returns obtained by using the Sharpe ratio also support our trading strategy. The results thus confirm that the early bird can catch more worms than the late bird in the Australian stock market. This simple trading method potentially benefits both institutional and individual investors include those who do not possess resources to implement complex trading strategies.

Considering the association between the Australian and other major stock markets documented by the large literature including Rapach et al. (2013), our study can be extended to other equity markets especially developed markets, which share many common characteristics with the Australian market. Furthermore, Gurgul and Syrek (2017) observe a similar U-or J-shaped intraday pattern in other equity markets, which we believe is one of the important factors to make our strategy work.

Lastly, one may argue that the effectiveness of day-trading strategies can be improved by incorporating the intraday news flow as one of the decision-making factors. To be more specific, the literature like Smales (2014b), Foucault et al. (2016) and Chapman (2018) document that both expected and unexpected intraday news, macroeconomic and industry/company specific ones, may substantially affect equity 
prices. As we take a long position following the level of excess overnight volatility, our current trading strategy to some extent takes into consideration of the news just before the market opening. Nevertheless, there are days when the market falls following unexpected negative news during the trading-hours. ${ }^{1}$ If we can take this into account, the performance of our strategy may be further improved.

As explained above, our strategy takes a long position at the opening of market. One way to incorporate unexpected news during the trading-hour, therefore, is adding another rule that if we observe strong negative news, we close the position before the market fully incorporates it. However, Smales (2014b) documents that a speedy trading of shorter than 30 seconds is required to obtain abnormal returns from trading with news items; this indicates that news items are quickly digested by the market. Thus, the additional rule explained above requires close monitoring of news and capability of swiftly executing trading. This makes our strategy overly complicated or impractical for small investors including individuals. We will leave this issue for future research.

\footnotetext{
${ }^{1}$ In theory, our strategy executes a trade even on those days, but obtains a superior profit.
} 


\section{References}

Admati, A.R., Pfleiderer, P., 1988. A theory of intraday patterns: Volume and price variability. The Review of Financial Studies 1, 3-40

Ahn, H.-J., Cheung, Y.-L., 1999. The intraday patterns of the spread and depth in a market without market makers: The stock exchange of Hong Kong. PacificBasin Finance Journal 7, 539-556

Aitken, M.J., Brown, P., Walter, T.S., 1994. Intraday patterns in returns, trading volume, volatility and trading frequency on SEATS. Accounting Research Centre, Department of Accounting, University of Sydney.

Andersen, T.G., Bollerslev, T., Cai, J., 2000. Intraday and interday volatility in the Japanese stock market. Journal of International Financial Markets, Institutions and Money 10, 107-130

Brailsford, T., 1995. Trading hours, intraday returns and volatility in Australia. Accounting Research Journal 8, 36-47

Chapman, K., 2018. Earnings notifications, investor attention, and the earnings announcement premium. Journal of Accounting and Economics 66, 222-243

Choe, H., Sik Shin, H., 1993. An analysis of interday and intraday return volatility evidence from the Korea Stock Exchange. Pacific-Basin Finance Journal 1, 175188

Foucault, T., Hombert, J., Roşu, I., 2016. News trading and speed. The Journal of Finance 71, 335-382

Groß-Klußmann, A., Hautsch, N., 2011. When machines read the news: Using automated text analytics to quantify high frequency news-implied market reactions. Journal of Empirical Finance 18, 321-340

Gurgul, H., Syrek, R., 2017. Trading volume and volatility patterns across selected Central European stock markets from microstructural perspective. Managerial Economics 18, 87-101

Harris, L., 1986. A transaction data study of weekly and intradaily patterns in stock returns. Journal of Financial Economics 16, 99-117

Hautsch, N., Hess, D., Veredas, D., 2011. The impact of macroeconomic news on quote 
adjustments, noise, and informational volatility. Journal of Banking and Finance 35, 2733-2746

Jain, P.C., Joh, G.-H., 1988. The dependence between hourly prices and trading volume. Journal of Financial and Quantitative Analysis 23, 269-283

Jayawardena, N.I., Todorova, N., Li, B., Su, J.-J., 2016. Forecasting stock volatility using after-hour information: Evidence from the Australian Stock Exchange. Economic Modelling 52, 592-608

Kalev, P.S., Liu, W.-M., Pham, P.K., Jarnecic, E., 2004. Public information arrival and volatility of intraday stock returns. Journal of Banking and Finance 28, 14411467

Madhavan, A., Richardson, M., Roomans, M., 1997. Why do security prices change? A transaction-level analysis of NYSE stocks. The Review of Financial Studies 10, $1035-1064$

Mcinish, T., H., Wood, R.A., 1990. A transactions data analysis of the variability of common stock returns during 1980-1984. Journal of Banking and Finance 14, 99-112

Mcinish, T.H., Wood, R.A., 1992. An analysis of intraday patterns in bid/ask spreads for NYSE stocks. The Journal of Finance 47, 753-764

Ohara, M., 2014. High -frequency trading and its impact on markets. Financial Analysts Journal 70, 18-27

Rapach, D.E., Strauss, J.K., Zhou, G., 2013. International stock return predictability:

What is the role of the united states? The Journal of Finance 68, 1633-1662

Roll, R., 1988. R2. The Journal of Finance 43, 541-566

Smales, L.A., 2014a. The impact of non-scheduled news on S\&P/ASX 50 stocks. JASSA, 19-24

Smales, L.A., 2014b. Reaction to nonscheduled news during financial crisis: Australian evidence. Applied Economics Letters 21, 1214-1220

Ultimate Trading Systems, 2005. The 10 a.m. rule for stocks and options. MetalStock, Greensborough

Wood, R.A., Mcinish, T.H., Ord, J.K., 1985. An investigation of transactions data for NYSE stocks. The Journal of Finance 40, 723-739

Wu, M.-E., Wang, C.-H., Chung, W.-H., 2017. Using trading mechanisms to investigate 
large futures data and their implications to market trends. Soft Computing 21, 2821-2834

Ying, C.C., 1966. Stock market prices and volumes of sales. Econometrica 34, 676-685 
Figure 1: Intraday distribution of average standard deviations and mean values of the relative average prices of S\&P/ASX 200 during each indicated time block against intraday average prices

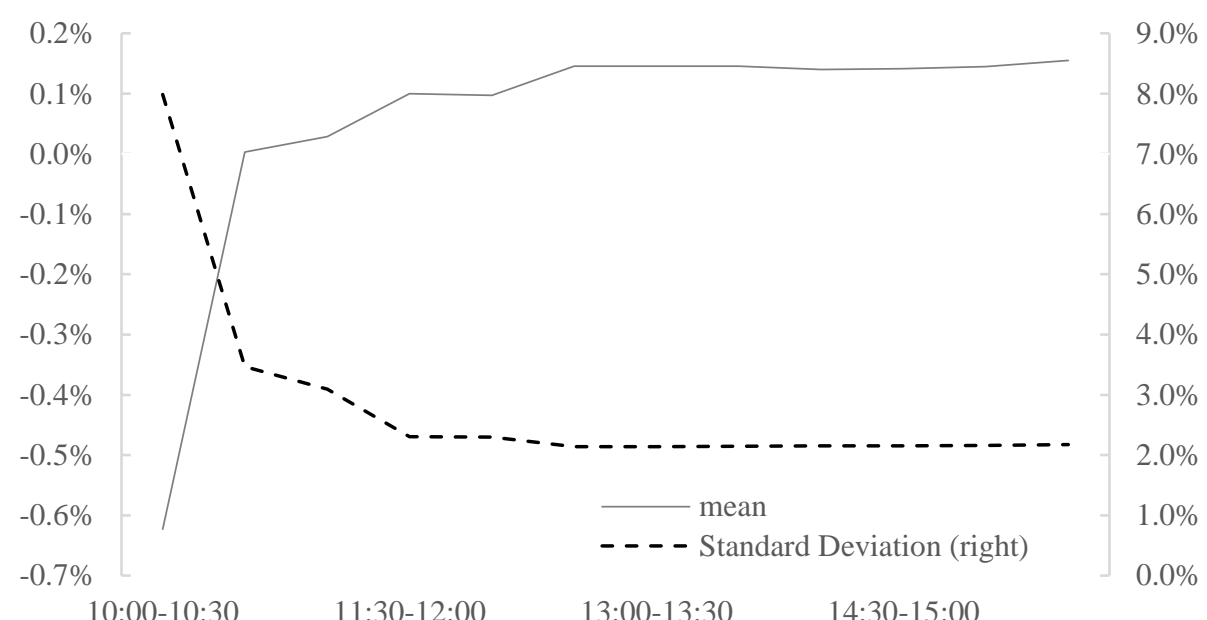


Table 1: Descriptive statistics: Australian S\&P/ASX 200 intraday relative average price

\begin{tabular}{lllllll}
\hline & Time-Blocks & Mean & Median & $\begin{array}{l}\text { Standard } \\
\text { Deviation }\end{array}$ & Min & \\
\hline $\mathbf{1}$ & $10: 00-10: 30$ & -0.62 & 0.01 & 7.99 & -100.00 & 6.52 \\
$\mathbf{2}$ & $10: 30-11: 00$ & 0.00 & 0.01 & 3.47 & -100.00 & 18.43 \\
$\mathbf{3}$ & $11: 00-11: 30$ & 0.03 & 0.00 & 3.10 & -100.00 & 29.76 \\
$\mathbf{4}$ & $11: 30-12: 00$ & 0.10 & 0.00 & 2.30 & -100.00 & 44.52 \\
$\mathbf{5}$ & $12: 00-12: 30$ & 0.10 & 0.00 & 2.30 & -100.00 & 44.42 \\
$\mathbf{6}$ & $12: 30-13: 00$ & 0.15 & 0.00 & 2.14 & -1.67 & 85.75 \\
$\mathbf{7}$ & $13: 00-13: 30$ & 0.15 & 0.00 & 2.14 & -2.70 & 85.72 \\
$\mathbf{8}$ & $13: 30-14: 00$ & 0.15 & 0.00 & 2.15 & -1.23 & 85.65 \\
$\mathbf{9}$ & $14: 00-14: 30$ & 0.14 & 0.00 & 2.15 & -1.28 & 85.50 \\
$\mathbf{1 0}$ & $14: 30-15: 00$ & 0.14 & 0.00 & 2.16 & -1.47 & 85.60 \\
$\mathbf{1 1}$ & $15: 00-15: 30$ & 0.14 & 0.01 & 2.16 & -2.06 & 85.79 \\
$\mathbf{1 2}$ & $15: 30-16: 00$ & 0.16 & 0.01 & 2.17 & -2.37 & 85.99 \\
\hline
\end{tabular}

Note: The table reports the descriptive statistics for relative average prices of S\&P/ASX 200 during each indicated time block against intraday average prices. 
Table 2: Frequency of intraday high/low price in different time blocks

\begin{tabular}{|c|c|c|c|c|c|c|c|c|c|c|c|c|c|}
\hline Year & & $\begin{array}{l}10: 00- \\
10: 30\end{array}$ & $\begin{array}{l}10: 30- \\
11: 00\end{array}$ & $\begin{array}{l}11: 00- \\
11: 30\end{array}$ & $\begin{array}{l}11: 30- \\
12: 00\end{array}$ & $\begin{array}{l}12: 00- \\
12: 30\end{array}$ & $\begin{array}{l}\text { 12:30- } \\
01: 00\end{array}$ & $\begin{array}{l}13: 00- \\
13: 30\end{array}$ & $\begin{array}{l}13: 30- \\
14: 00\end{array}$ & $\begin{array}{c}14: 00- \\
14: 30\end{array}$ & $\begin{array}{l}14: 30- \\
15: 00\end{array}$ & $\begin{array}{l}15: 00- \\
15: 30\end{array}$ & $\begin{array}{l}15: 30- \\
16: 00\end{array}$ \\
\hline \multirow[t]{2}{*}{2000} & High & 13.21 & 9.43 & 5.66 & 3.77 & 0.00 & 0.00 & 3.77 & 5.66 & 1.89 & 18.87 & 18.87 & 18.87 \\
\hline & Low & 19.63 & 13.08 & 7.48 & 5.61 & 3.74 & 1.87 & 5.61 & 3.74 & 5.61 & 5.61 & 13.08 & 14.95 \\
\hline \multirow[t]{2}{*}{2001} & High & 19.33 & 7.64 & 4.77 & 5.73 & 2.86 & 4.30 & 2.86 & 4.77 & 6.21 & 6.68 & 8.11 & 26.73 \\
\hline & Low & 23.67 & 6.28 & 2.90 & 4.83 & 4.35 & 3.38 & 3.38 & 7.25 & 8.21 & 8.21 & 7.73 & 19.81 \\
\hline \multirow[t]{2}{*}{2002} & High & 22.07 & 9.09 & 6.22 & 4.31 & 4.31 & 3.83 & 3.83 & 6.22 & 3.35 & 6.70 & 7.18 & 22.97 \\
\hline & Low & 22.33 & 4.85 & 8.74 & 2.91 & 5.83 & 1.94 & 4.37 & 3.40 & 11.65 & 7.77 & 8.74 & 17.48 \\
\hline \multirow[t]{2}{*}{2003} & High & 19.72 & 10.67 & 7.89 & 2.78 & 4.18 & 2.78 & 3.25 & 4.64 & 6.50 & 6.96 & 7.89 & 22.74 \\
\hline & Low & 22.40 & 5.24 & 7.14 & 1.43 & 4.76 & 2.86 & 1.90 & 6.19 & 11.90 & 8.10 & 8.10 & 22.38 \\
\hline \multirow[t]{2}{*}{2004} & High & 17.18 & 11.29 & 5.18 & 5.65 & 4.24 & 3.76 & 5.18 & 5.18 & 8.94 & 7.53 & 8.94 & 16.94 \\
\hline & Low & 22.12 & 9.62 & 5.77 & 2.88 & 3.85 & 5.29 & 3.37 & 3.37 & 8.17 & 7.21 & 11.54 & 16.83 \\
\hline \multirow[t]{2}{*}{2005} & High & 17.73 & 6.62 & 6.15 & 6.15 & 4.73 & 4.73 & 6.62 & 5.67 & 4.73 & 8.98 & 8.51 & 19.39 \\
\hline & Low & 19.34 & 11.32 & 7.08 & 4.25 & 2.36 & 2.36 & 3.77 & 4.25 & 5.66 & 7.55 & 10.38 & 21.70 \\
\hline \multirow[t]{2}{*}{2006} & High & 18.14 & 11.63 & 6.51 & 5.58 & 3.72 & 3.72 & 3.72 & 6.51 & 3.72 & 6.05 & 8.37 & 22.33 \\
\hline & Low & 19.63 & 8.78 & 4.16 & 3.70 & 5.08 & 3.70 & 6.47 & 7.85 & 8.31 & 5.54 & 8.78 & 18.01 \\
\hline \multirow[t]{2}{*}{2007} & High & 19.33 & 10.50 & 6.21 & 5.25 & 3.34 & 2.39 & 4.30 & 4.77 & 4.30 & 7.64 & 9.07 & 22.91 \\
\hline & Low & 18.83 & 8.97 & 8.97 & 4.04 & 3.59 & 6.28 & 4.93 & 4.04 & 5.83 & 8.07 & 9.42 & 17.04 \\
\hline \multirow[t]{2}{*}{2008} & High & 23.88 & 8.98 & 5.20 & 3.78 & 2.84 & 4.26 & 4.26 & 3.31 & 4.73 & 6.62 & 8.04 & 24.11 \\
\hline & Low & 16.82 & 7.48 & 7.01 & 6.54 & 4.67 & 5.14 & 6.07 & 6.54 & 6.07 & 7.94 & 9.35 & 16.36 \\
\hline \multirow[t]{2}{*}{2009} & High & 18.72 & 10.05 & 5.48 & 5.02 & 4.57 & 6.39 & 4.11 & 2.74 & 7.31 & 3.65 & 9.13 & 22.83 \\
\hline & Low & 18.82 & 7.26 & 9.07 & 4.99 & 3.63 & 4.08 & 4.54 & 5.44 & 6.35 & 8.62 & 9.98 & 17.23 \\
\hline \multirow[t]{2}{*}{2010} & High & 20.55 & 8.78 & 9.24 & 6.00 & 4.62 & 4.62 & 3.70 & 4.16 & 4.16 & 5.08 & 7.85 & 21.25 \\
\hline & Low & 16.78 & 4.60 & 5.06 & 6.44 & 4.60 & 4.14 & 3.22 & 7.82 & 5.06 & 11.03 & 10.11 & 21.15 \\
\hline \multirow[t]{2}{*}{2011} & High & 21.33 & 11.37 & 5.21 & 4.74 & 3.79 & 3.79 & 3.32 & 2.84 & 7.58 & 9.00 & 6.64 & 20.38 \\
\hline & Low & 17.13 & 9.72 & 6.48 & 5.56 & 6.94 & 6.94 & 5.56 & 5.09 & 5.09 & 6.02 & 4.63 & 20.83 \\
\hline \multirow[t]{2}{*}{2012} & High & 19.63 & 11.09 & 6.93 & 6.93 & 4.62 & 4.16 & 5.54 & 3.70 & 5.08 & 6.00 & 7.85 & 18.48 \\
\hline & Low & 18.14 & 9.30 & 6.51 & 6.98 & 5.12 & 6.51 & 6.51 & 3.72 & 6.51 & 4.19 & 6.51 & 20.00 \\
\hline \multirow[t]{2}{*}{2013} & High & 18.16 & 8.28 & 7.82 & 8.28 & 5.98 & 4.60 & 6.44 & 6.44 & 5.98 & 3.68 & 8.28 & 16.09 \\
\hline & Low & 19.25 & 9.86 & 5.16 & 7.51 & 8.45 & 7.04 & 3.76 & 6.10 & 4.23 & 6.57 & 7.98 & 14.08 \\
\hline \multirow[t]{2}{*}{2014} & High & 20.56 & 8.88 & 6.54 & 4.21 & 7.01 & 4.21 & 3.74 & 4.21 & 6.07 & 2.34 & 6.54 & 25.70 \\
\hline & Low & 16.89 & 8.44 & 8.89 & 4.00 & 8.89 & 4.00 & 5.78 & 3.56 & 5.78 & 8.44 & 10.67 & 14.67 \\
\hline \multirow[t]{2}{*}{2015} & High & 21.41 & 9.58 & 6.39 & 3.19 & 3.83 & 4.47 & 2.56 & 5.11 & 3.83 & 8.95 & 6.39 & 24.28 \\
\hline & Low & 19.63 & 3.68 & 3.07 & 7.36 & 4.29 & 7.36 & 4.91 & 4.29 & 7.98 & 9.20 & 4.91 & 23.31 \\
\hline
\end{tabular}

Note: The table reports the percentage of intraday high or low price to be recorded in each time block during the indicated year. 
Table 3: Mean and standard deviation of relative intraday average price in different time block

\begin{tabular}{|c|c|c|c|c|c|c|c|c|c|c|c|c|c|}
\hline & & $\begin{array}{c}10: 00- \\
10: 30\end{array}$ & $\begin{array}{c}10: 30- \\
11: 00\end{array}$ & $\begin{array}{c}11: 00- \\
11: 30\end{array}$ & $\begin{array}{l}11: 30- \\
12: 00\end{array}$ & $\begin{array}{c}12: 00- \\
12: 30\end{array}$ & $\begin{array}{l}12: 30- \\
01: 00\end{array}$ & $\begin{array}{l}13: 00- \\
13: 30\end{array}$ & $\begin{array}{l}13: 30- \\
14: 00\end{array}$ & $\begin{array}{l}14: 00- \\
14: 30\end{array}$ & $\begin{array}{c}14: 30- \\
15: 00\end{array}$ & $\begin{array}{c}15: 00- \\
15: 30\end{array}$ & $\begin{array}{c}15: 30 \\
16: 00\end{array}$ \\
\hline \multicolumn{14}{|c|}{ GICS (Global Industry Classification) Indices } \\
\hline \multirow[t]{2}{*}{$\overline{\text { AXFJ }}$} & Mean & -0.49 & 0.00 & -0.01 & 0.07 & 0.07 & 0.12 & 0.12 & 0.12 & 0.12 & 0.12 & 0.12 & 0.13 \\
\hline & S.D & 7.10 & 3.08 & 3.07 & 2.22 & 2.22 & 2.04 & 2.05 & 2.05 & 2.05 & 2.06 & 2.07 & 2.09 \\
\hline \multirow[t]{2}{*}{ AXNJ } & Mean & -0.48 & 0.01 & 0.00 & 0.07 & 0.07 & 0.12 & 0.12 & 0.12 & 0.11 & 0.10 & 0.11 & 0.12 \\
\hline & S.D & 7.10 & 3.08 & 3.07 & 2.23 & 2.22 & 2.04 & 2.04 & 2.05 & 2.05 & 2.06 & 2.06 & 2.08 \\
\hline \multirow[t]{2}{*}{ AXJR } & Mean & -0.73 & -0.11 & 0.03 & 0.02 & 0.10 & 0.10 & 0.10 & 0.25 & 0.24 & 0.24 & 0.24 & 0.25 \\
\hline & S.D & 8.72 & 4.88 & 3.69 & 3.69 & 3.19 & 3.19 & 3.18 & 4.33 & 4.34 & 4.34 & 4.34 & 4.34 \\
\hline \multicolumn{14}{|c|}{ Individual Assets } \\
\hline \multirow[t]{2}{*}{ CBA } & Mean & 1.54 & 0.03 & 0.53 & 0.42 & 0.18 & 0.00 & -0.03 & 0.20 & -0.48 & -0.45 & -0.09 & -3.38 \\
\hline & S.D & 14.57 & 10.95 & 8.48 & 9.35 & 8.99 & 8.95 & 7.63 & 7.45 & 9.89 & 11.29 & 11.41 & 15.66 \\
\hline \multirow[t]{2}{*}{ NAB } & Mean & -0.85 & -0.09 & 0.01 & 0.05 & 0.09 & 0.13 & 0.14 & 0.21 & 0.20 & 0.21 & 0.38 & 0.38 \\
\hline & S.D & 9.23 & 4.80 & 3.97 & 3.69 & 3.45 & 3.35 & 3.35 & 3.90 & 3.90 & 3.93 & 9.60 & 9.68 \\
\hline \multirow[t]{2}{*}{ ANZ } & Mean & -0.67 & 0.00 & 0.03 & 0.10 & 0.11 & 0.15 & 0.15 & 0.16 & 0.15 & 0.15 & 0.16 & 0.16 \\
\hline & S.D & 8.22 & 3.52 & 3.14 & 2.35 & 2.35 & 2.19 & 2.19 & 2.20 & 2.21 & 2.23 & 2.24 & 2.27 \\
\hline \multirow[t]{2}{*}{ BHP } & Mean & -0.69 & 0.05 & 0.08 & 0.11 & 0.10 & 0.15 & 0.15 & 0.15 & 0.14 & 0.14 & 0.14 & 0.15 \\
\hline & S.D & 8.37 & 3.14 & 2.72 & 2.29 & 2.28 & 2.12 & 2.12 & 2.13 & 2.13 & 2.13 & 2.14 & 2.16 \\
\hline
\end{tabular}

Note: The figures reported are in percentage terms and for the sample period of 02/10/2000-02/10/2015. The lowest mean value obtained per block is in boldface. The highest mean value obtained per block is in italics. AXFJ - the ASX Financial Index, AXNJ - the ASX Industrial Index, AXJR - the ASX Resources Index, CBA - Commonwealth Bank of Australia, NAB - National Australia Bank, and BHP - BHP Billiton. 
Table 4: Performance of ours and other sixty-six possible day-trading combinations for the S\&P/ASX 200 index

\begin{tabular}{|c|c|c|c|c|c|c|c|c|c|}
\hline Buy and Sell Blocks & Our strategy & 1 to 2 & 1 to 3 & 1 to 4 & 1 to 5 & 1 to 6 & 1 to 7 & 1 to 8 & 1 to 9 \\
\hline Annualised Returns & 9.3 & -0.37 & -2.42 & -3.68 & -4.21 & -4.38 & -4.29 & -4.44 & -5.80 \\
\hline Buy and Sell Blocks & 1 to 10 & 1 to 11 & 1 to 12 & 2 to 3 & 2 to 4 & 2 to 5 & 2 to 6 & 2 to 7 & 2 to 8 \\
\hline Annualised Returns & -5.51 & -4.63 & -2.10 & -2.07 & -3.35 & -3.96 & -4.10 & -4.02 & -4.14 \\
\hline Buy and Sell Blocks & 2 to 9 & 2 to 10 & 2 to 11 & 2 to 12 & 3 to 4 & 3 to 5 & 3 to 6 & 3 to 7 & 3 to 8 \\
\hline Annualised Returns & -5.42 & -5.14 & -4.30 & -1.73 & -1.28 & -1.89 & -2.03 & -1.95 & -2.06 \\
\hline Buy and Sell Blocks & 3 to 9 & 3 to 10 & 3 to 11 & 3 to 12 & 4 to 5 & 4 to 6 & 4 to 7 & 4 to 8 & 4 to 9 \\
\hline Annualised Returns & -3.34 & -3.04 & -2.20 & 0.37 & -0.61 & -0.74 & -0.65 & -0.73 & -2.01 \\
\hline Buy and Sell Blocks & 4 to 10 & 4 to 11 & 4 to 12 & 5 to 6 & 5 to 7 & 5 to 8 & 5 to 9 & 5 to 10 & 5 to 11 \\
\hline Annualised Returns & -1.70 & -0.86 & 1.73 & -0.13 & -0.04 & -0.12 & -1.40 & -1.10 & -0.25 \\
\hline Buy and Sell Blocks & 5 to 12 & 6 to 7 & 6 to 8 & 6 to 9 & 6 to 10 & 6 to 11 & 6 to 12 & 7 to 8 & 7 to 9 \\
\hline Annualised Returns & 2.33 & 0.08 & 0.00 & -1.29 & -0.98 & -0.13 & 2.46 & -0.08 & -1.37 \\
\hline Buy and Sell Blocks & 7 to 10 & 7 to 11 & 7 to 12 & 8 to 9 & 8 to 10 & 8 to 11 & 8 to 12 & 9 to 10 & 9 to 11 \\
\hline Annualised Returns & -1.07 & -0.22 & 2.37 & -1.29 & -0.99 & -0.14 & 2.45 & 0.30 & 1.15 \\
\hline Buy and Sell Blocks & 9 to 12 & 10 to 11 & 10 to 12 & 11 to 12 & & & & & \\
\hline Annualised Returns & 3.73 & 0.85 & 3.43 & 2.57 & & & & & \\
\hline
\end{tabular}

Note: The numbers in the "Buy and Sell Blocks" column show timing of the trading (the first number indicates when to buy and the second indicates when to sell), except for our strategy. For example, "1 to 2" means buy at the first time block and sell at the second time block. The trading hours at the ASX is divided into 12 time blocks and the first block represents 10:00-10:30 and the twelfth represents 15:30-16:00. 
Table 5: Paired t-tests comparing the returns obtained from our strategy against other day-trade methods

\begin{tabular}{|c|c|c|c|c|c|c|c|c|c|}
\hline $\begin{array}{c}\text { Buy and Sell } \\
\text { Blocks }\end{array}$ & 1 to 2 & 1 to 3 & 1 to 4 & 1 to 5 & 1 to 6 & 1 to 7 & 1 to 8 & 1 to 9 & 1 to 10 \\
\hline T-statistic & -9.59 & -8.14 & -8.26 & -9.36 & -9.97 & -10.35 & -10.97 & -11.12 & -11.45 \\
\hline $\begin{array}{l}\text { Buy and Sell } \\
\text { Blocks }\end{array}$ & 1 to 11 & 1 to 12 & 2 to 3 & 2 to 4 & 2 to 5 & 2 to 6 & 2 to 7 & 2 to 8 & 2 to 9 \\
\hline T-statistic & -11.33 & -11.56 & -6.68 & -6.84 & -7.94 & -8.53 & -8.91 & -9.53 & -9.61 \\
\hline $\begin{array}{c}\text { Buy and Sell } \\
\text { Blocks }\end{array}$ & 2 to 10 & 2 to 11 & 2 to 12 & 3 to 4 & 3 to 5 & 3 to 6 & 3 to 7 & 3 to 8 & 3 to 9 \\
\hline T-statistic & -9.96 & -9.85 & -10.09 & -7.92 & -9.03 & -9.63 & -10.03 & -10.67 & -10.78 \\
\hline $\begin{array}{c}\text { Buy and Sell } \\
\text { Blocks }\end{array}$ & 3 to 10 & 3 to 11 & 3 to 12 & 4 to 5 & 4 to 6 & 4 to 7 & 4 to 8 & 4 to 9 & 4 to 10 \\
\hline T-statistic & -11.12 & -11.01 & -11.26 & -9.25 & -9.78 & -10.26 & -10.87 & -11.01 & -11.37 \\
\hline $\begin{array}{c}\text { Buy and Sell } \\
\text { Blocks }\end{array}$ & 4 to 11 & 4 to 12 & 5 to 6 & 5 to 7 & 5 to 8 & 5 to 9 & 5 to 10 & 5 to 11 & 5 to 12 \\
\hline T-statistic & -11.23 & -11.48 & -8.61 & -9.08 & -9.69 & -9.81 & -10.20 & -10.06 & -10.31 \\
\hline $\begin{array}{c}\text { Buy and Sell } \\
\text { Blocks }\end{array}$ & 6 to 7 & 6 to 8 & 6 to 9 & 6 to 10 & 6 to 11 & 6 to 12 & 7 to 8 & 7 to 9 & 7 to 10 \\
\hline T-statistic & -8.54 & -9.17 & -9.26 & -9.64 & -9.50 & -9.75 & -8.72 & -8.83 & -9.22 \\
\hline $\begin{array}{c}\text { Buy and Sell } \\
\text { Blocks }\end{array}$ & 7 to 11 & 7 to 12 & 8 to 9 & 8 to 10 & 8 to 11 & 8 to 12 & 9 to 10 & 9 to 11 & 9 to 12 \\
\hline T-statistic & -9.07 & -9.33 & -8.20 & -8.59 & -8.44 & -8.69 & -8.48 & -8.33 & -8.59 \\
\hline $\begin{array}{c}\text { Buy and Sell } \\
\text { Blocks }\end{array}$ & 10 to 11 & 10 to 12 & 11 to 12 & & & & & & \\
\hline T-statistic & -7.94 & -8.20 & -8.35 & & & & & & \\
\hline
\end{tabular}

Note: The numbers in the "Buy and Sell Blocks" column show timing of the trading (the first number indicates when to buy and the second indicates when to sell), except for our strategy. For example, "1 to 2" means buy at the first time block and sell at the second time block. The trading hours at the ASX is divided into 12 time blocks and the first block represents $10: 00-10: 30$ and the twelfth represents 15:30-16:00. T-statistic value for the hypothesis, $\left[\mathrm{H}_{0}: \operatorname{HPR}\right.$ (of our strategy) $=\mathrm{HPR}_{\mathrm{i}}(\mathrm{i}=1,2, \ldots . .66$ ), is shown. The results are all significant at the $5 \%$ level of significance. 
Table 6: Sharpe ratios of our strategy and other day-trading methods

\begin{tabular}{|c|c|c|c|c|c|c|c|c|c|}
\hline Buy and Sell Blocks & Our strategy & 1 to 2 & 1 to 3 & 1 to 4 & 1 to 5 & 1 to 6 & 1 to 7 & 1 to 8 & 1 to 9 \\
\hline Sharpe Ratio & 2.53 & -3.71 & -7.49 & -7.62 & -9.49 & -1.44 & -1.86 & -1.82 & -1.98 \\
\hline Buy and Sell Blocks & 1 to 10 & 1 to 11 & 1 to 12 & 2 to 3 & 2 to 4 & 2 to 5 & 2 to 6 & 2 to 7 & 2 to 8 \\
\hline Sharpe Ratio & -1.32 & -2.06 & -2.26 & -4.93 & -5.18 & -7.17 & -8.14 & -8.62 & -9.62 \\
\hline Buy and Sell Blocks & 2 to 9 & 2 to 10 & 2 to 11 & 2 to 12 & 3 to 4 & 3 to 5 & 3 to 6 & 3 to 7 & 3 to 8 \\
\hline Sharpe Ratio & -9.7 & -1.12 & -9.87 & -1.14 & -3.97 & -2.49 & -2.94 & -2.4 & -2.92 \\
\hline Buy and Sell Blocks & 3 to 9 & 3 to 10 & 3 to 11 & 3 to 12 & 4 to 5 & 4 to 6 & 4 to 7 & 4 to 8 & 4 to 9 \\
\hline Sharpe Ratio & -2.14 & -2.28 & -2.36 & -2.79 & -4.91 & -3.39 & -3.88 & -3.99 & -2.43 \\
\hline Buy and Sell Blocks & 4 to 10 & 4 to 11 & 4 to 12 & 5 to 6 & 5 to 7 & 5 to 8 & 5 to 9 & 5 to 10 & 5 to 11 \\
\hline Sharpe Ratio & -2.06 & -2.8 & -2.9 & -3.19 & -3.71 & -2 & -2.04 & -2.87 & -2.46 \\
\hline Buy and Sell Blocks & 5 to 12 & 6 to 7 & 6 to 8 & 6 to 9 & 6 to 10 & 6 to 11 & 6 to 12 & 7 to 8 & 7 to 9 \\
\hline Sharpe Ratio & -2.75 & -4.98 & -3.35 & -3.13 & -2.59 & -2.43 & -4.24 & -4.01 & -3.9 \\
\hline Buy and Sell Blocks & 7 to 10 & 7 to 11 & 7 to 12 & 8 to 9 & 8 to 10 & 8 to 11 & 8 to 12 & 9 to 10 & 9 to 11 \\
\hline Sharpe Ratio & -3.99 & -2.65 & -2.94 & -4.36 & -3.14 & -2.96 & -2.12 & -4.48 & -3.72 \\
\hline Buy and Sell Blocks & 9 to 12 & 10 to 11 & 10 to 12 & 11 to 12 & & & & & \\
\hline Sharpe Ratio & -3.4 & -4.64 & -3.93 & -5.35 & & & & & \\
\hline
\end{tabular}

Note: The numbers in the "Buy and Sell Blocks" column show timing of the trading (the first number indicates when to buy and the second indicates when to sell), except for our strategy. For example, "1 to 2" means buy at the first time block and sell at the second time block. The trading hours at the ASX is divided into 12 time blocks and the first block represents 10:00-10:30 and the twelfth represents 15:30-16:00. The Sharpe ratio is calculated as Sharpe Ratio $=\frac{H P R_{I}-R_{F}}{S D\left(H P R_{i}\right)}, i=1,2, \ldots 66$, where $R_{F}$ is the cash rate published by the Reserve Bank Australia and $S D\left(H P R_{i}\right)$ is the standard deviation of the holding period return of the $i^{\text {th }}$ trading method. 